\title{
A função didático-pedagógica da linguagem musical: uma possibilidade na educação
}

\section{Music language didactical pedagogical role: a chance in education}

\author{
Marcos Antonio Correia ${ }^{1}$
}

\begin{abstract}
RESUMO
No artigo apresenta-se a música como elemento imprescindível na educação, pelo seu valor artístico, estético, cognitivo e emocional. Pedagogicamente, através da criatividade, a linguagem musical oferece possibilidades interdisciplinares, enriquecendo o processo educacional. O texto estruturase em três momentos, sendo que o primeiro posiciona os conhecimentos científicos na atualidade, ao mesmo tempo em que destaca a importância do ensino para a disseminação dos saberes do homem. Na sequência, evidencia-se a linguagem musical no processo ensino-aprendizagem e, em um terceiro momento, a criatividade musical surge como elemento interdisciplinar, além da presença da emoção - mais a razão - como elemento indispensável em qualquer momento do processo ensino-aprendizagem e consequentemente da educação como um todo.

Palavras-chave: música; emoção-razão; educação.
\end{abstract}

\begin{abstract}
In this paper, music is presented as an indispensable element in education because of its artistic, esthetic, cognitive, and emotional value. Pedagogically, through creativity, music language provides interdisciplinary possibilities, enriching the educational process. The text is structured by three parts. At first, scientific knowledge is set at the present time as well as the importance of teaching for the spreading of men's knowledge is emphasized. Secondly, music language in the teaching-learning process is accentuated and, in a third moment, musical creativity takes place as
\end{abstract}

1 Professor do departamento de geografia da FAFI e discente do Programa de Mestrado/ Doutorado em geografia da UFPR. 
an interdisciplinary element, in addition to the presence of emotion - plus sense - as a necessary factor in any period of the teaching-learning process and consequently of education as a whole.

Keywords: music; emotion-reason; education.

\section{Introdução}

O artigo "A função didático-pedagógica da linguagem musical: uma possibilidade na educação” busca chamar a atenção para as necessidades pedagógicas que se apresentam atualmente à educação. Pois o ensino, neste mundo, dito por muitos de pós-moderno, tornou-se relativo, no qual as possibilidades apresentam-se diferenciadas e adaptáveis dependendo do lugar e tempo a que pertence.

Nesse sentido novas possibilidades devem ser experimentadas, como é o caso da linguagem musical no processo ensino-aprendizagem, pois esta resgata outras facetas do processo educacional, como a emoção e a criatividade, as quais estão envolvidas pelo conteúdo interdisciplinar, subjetivo e estético dessa linguagem artística. Por conseguinte, o texto coloca algumas categorias constantes de teorias que abordam Inteligências Múltiplas e Inteligência Emocional.

$\mathrm{O}$ artigo estrutura-se em três momentos, sendo que o primeiro posiciona os conhecimentos científicos na atualidade, ao mesmo tempo em que destaca a importância do ensino para a disseminação dos saberes humanos. Na sequência evidencia-se a linguagem musical no processo ensino-aprendizagem e a criatividade musical como elemento interdisciplinar bem como a presença da emoção - mais a razão - como elemento indispensável em qualquer momento do processo ensino-aprendizagem e consequentemente da educação como um todo.

\section{1 - Posicionamento científico e pedagógico dos saberes}

No que tange ao problema pedagógico, Immanuel Kant (segundo GALEFFI, 1986, p. 263). afirma que este é "o mais grave dos problemas e o mais árduo que o homem possa propor-se”, o ser humano é o único a ser educado, sem a qual - a educação - ele não poderá atingir sua plena razão e liberdade. O 
autor afirma também que a educação é uma arte, mas que deve ser organizada de forma sistemática e científica, balizada por princípios como o da disciplina, pois esta é o freio da natureza selvagem; promoção da instrução geral e da cultura (distinguia algumas habilidades como: ler e escrever - úteis em todas as ocasiões - a música, para nos tornar amáveis) e várias outras as quais considerava infinita, também destacou a prudência e a moralidade na questão educacional (GALEFFI, 1986).

O pensamento de Kant, mesmo reforçando aspectos racionais na construção dos saberes, aponta, de forma subjacente, para questões emocionais, subjetivas e estéticas quando destaca a liberdade e a utilização da música, a qual sempre esteve presente na formação cultural e científica, desde os primórdios da humanidade, passando pelos clássicos tempos dos gregos e romanos, Idade Média, Moderna, até os dias atuais. Sendo que na atualidade os paradigmas levam a outra realidade que suscitam outras abordagens, tanto em relação aos saberes, principalmente de ordem científica, e suas respectivas disseminações.

Na edição especial da Revista Nova Escola (v. 2, p. 8-9) consta que, mesmo antes da existência de escolas, a educação já era tema de grandes pensadores da antiga Grécia. Sendo que no pensamento sofista a educação se apresenta à vida prática, já para Sócrates era algo mais abrangente envolvendo a sabedoria - conhecer o mundo e a si mesmo -, contribuindo enormemente para o que viria a ser ciência e educação até os dias atuais.

Baseado na precipuosidade dos pensamentos platônicos e aristotélicos, a Revista Nova Escola (v. 2, p. 8-9) propõe interessante exposição para se acompanhar, de forma genérica, a evolução do pensamento pedagógico ocidental. Estabelece sequência genealógica que parte de Sócrates, bifurcando-se em dois grandes troncos filosóficos e históricos, demarcados de um lado pelo realismo ${ }^{2}$ de Aristóteles e de outro pelo idealismo ${ }^{3}$ de Platão.

Acompanhando o primeiro concentram-se algumas variantes como: o tomismo, o humanismo, o empirismo, o materialismo, o positivismo, o liberalismo, o evolucionismo, o marxismo, o pós-marxismo, o behaviorismo, o construtivismo e o cognitivismo. No caso do idealismo, coadunam-se pensamentos como: do neoplatonismo, da reforma, da contrarreforma, do racionalismo, do naturalismo, do idealismo alemão, da educação progressista, da fenomenologia,

2 Concepção filosófica segundo a qual existe uma realidade exterior, determinada, autônoma, independente do conhecimento que se pode ter sobre ela. (JAPIASSÚ; MARCONDES, p.231).

3 O termo "idealismo" engloba, na história da filosofia, diferentes correntes de pensamento que têm em comum a interpretação da realidade do mundo exterior ou material em termos do interior, subjetivo ou espiritual. [...] redução do conhecimento ao sujeito conhecedor, [...] "realismo da idéias", [...] para Platão. (Ibidem 135) 
da escola nova e do existencialismo.

Observa-se a indissociabilidade entre a educação e ciência, sendo que essa última assume importante condição na hierarquia dos níveis de conhecimento e seus saberes. Contudo, na mesma proporção em se que avançam os saberes, observa-se a necessidade de tratamento e ajustes em suas formas de disseminações, das quais a educação formal se apresenta. Nesse sentido, Capra (2002, p. 14-19) diz que atualmente o mundo está conectado, e os fenômenos naturais, sociais e psicológicos estão interligados e cada vez mais interdependentes, e nesse contexto as elaborações sistêmicas e cartesianas, assim como o pensamento positivista, não estão dando conta de satisfazer o equilíbrio individual e social, suscitados pela sociedade como um todo.

Constata-se, também, que a sociedade moderna, em processo de globalização, passa por momentos de inversões e adaptações em seu projeto humano vigente desde o século XVIII, no qual a razão se fez presente em detrimento da emoção na elaboração e disseminação dos conhecimentos científicos e dos saberes de modo geral. Essas alterações na forma de pensar da sociedade estabelecem questionamentos por parte de alguns pensadores que colocam em dúvida o primado da razão em relação à emoção. Nesse sentido, atualmente, coloca-se em evidência o chamado pós-modernismo, subentendido como consequente do modernismo.

Quanto à modernidade, Japiassu e Marcondes (1999, p. 185) dizem que ela apresenta-se como uma concepção de mundo consagrada no Renascimento - estruturada por Bacon, Galileu e Descartes - e que se colocava em oposição à escolástica e ao espírito medieval. Hoje, a modernidade estabelece controvérsia de ordem filosófica envolvendo, principalmente, as áreas sociais, artísticas e culturais da humanidade. Por outro lado, contrapondo-se à modernidade - defendida por alguns, destacando a importância e seu inacabamento, tendo na razão seu principal condutor - vem a ideia de pós-modernidade a qual não condena a razão, mas valoriza, também, a emoção como forma de emancipação do gênero humano, pois é por meio da arte, da criatividade e de seu sentimento que o ser atinge sua plenitude.

O ser humano é naturalmente um fator de interiorização privilegiado. Parece que o homem pode sentir e conhecer diretamente as propriedades íntimas de seu físico. A obscuridade do eu sinto predomina sobre a clareza do eu vejo. O homem tem consciência de ser, por seu corpo tomado de um vago sentimento, uma substância. (BACHELARD, 1996, p. 159). 
Conclui-se que a sociedade atual evoluiu em muitos segmentos mas, por questões sociais e políticas, alguns grupos menores, mas mais bem representados, acabaram não respeitando princípios já propagados desde a Revolução Francesa, ou seja, Igualdade, Liberdade e Fraternidade, fazendo desses princípios apenas conteúdos teóricos dificilmente respeitados, os quais foram usados apenas para aumentar a hegemonia e o poder de alguns em detrimento da maioria. Mas é importante notar que alguns setores dessa maioria menos favorecida acabaram se conscientizando e se organizando, provocando novas expectativas e solicitando mudanças e tomada de novos rumos à humanidade.

Sem dúvida, para atravessarmos o mar de incertezas, necessitamos da mediação da ciência e da pedagogia, as quais devem ser repensadas e aplicadas dentro da nova concepção de mundo que nos envolve atualmente. Bachelard (1996, p. 310) faz uma reflexão pertinente nesse sentido dizendo que: "Só há ciência se a Escola for permanente. É essa escola que a ciência deve fundar. Então, os interesses sociais estarão definitivamente invertidos: a Sociedade será feita para a Escola e não a escola para a Sociedade”.

Essas mudanças estruturais da sociedade mundial também são reveladas nos preceitos educacionais de várias nações, inclusive a brasileira. Isso é observado no Brasil (BRASIL, 1999, p. 27) onde as recomendações constantes da Comissão Internacional sobre Educação para o século XXI, absorvidas pela Lei de Diretrizes e Base da Educação Nacional (LDB 9.394/96), apontam que a educação deve cumprir um triplo papel, ou seja, de ordem econômica, científica e cultural, bem como deve estruturar-se em quatro alicerces: aprender a conhecer, aprender a fazer, aprender a viver e aprender a ser.

Esse texto sugere que, no meio educacional, os aprenderes "conhecer e fazer” estão mais presentes na cultura ocidental, e que os aprenderes "viver e ser”, carecem mais atenção. Por isso a ideia de introduzir a natureza racional e, principalmente, subjetiva e emocional da música no processo ensino-aprendizagem, pois a música, com seu caráter e natureza interdisciplinar, pode se transformar em instrumento metodológico e didático-pedagógico de grande utilidade.

Como se percebe, o texto ora abordado, por questões de extensão, não comporta discussões mais aprofundadas sobre políticas, estrutura, método, teorias e suas respectivas correntes educacionais, mas algumas indicações reflexivas se fazem pertinentes. Nesse particular, destaca-se a discussão sobre o fundamental papel da educação na vida das pessoas na atualidade, bem como de sua práxis cotidiana no processo ensino aprendizagem.

Portanto, independente de pensamento científico e pedagógico, bem como toda a estrutura epistêmica que os envolve: conhecimento e sua disseminação; há que se destacar o indivíduo em seu ambiente sociocultural, o qual se reflete nas ações escolares, hoje cada vez mais representadas pelo construtivismo, suas 
variantes e subjacências, as quais ultrapassam os paradigmas reducionistas do empirismo e do racionalismo.

Ainda é importante destacar que a emoção, afetividade e subjetividade, embora tacitamente em alguns momentos, sempre estiveram e estão presentes - desde as mais antigas, conservadoras e reducionistas, até as mais abertas, dinâmicas e contemporâneas correntes pedagógicas - nas concepções educacionais.

Avaliando essas informações percebe-se que a empreitada educacional é complexa e árdua, mas algumas iniciativas podem contribuir para a melhoria do ensino, como a proposta aventada até aqui. Nota-se, também, que o texto não oferece extensão suficiente para tratar de tema tão amplo, mesmo porque, não ousa a pretensão de discutir teorias educacionais que poderiam servir de aporte a ele mencionado. Contudo, procura apresentar algumas iniciativas referentes à inteligência e aprendizagem, como a Inteligência Emocional e as Inteligências Múltiplas, associadas à natureza interdisciplinar, emocional e racional da música, bem como destacar o papel da linguagem musical e da criatividade nesse processo.

O pesquisador Goleman (2008), em entrevista, relata que a Inteligência Emocional identifica a maneira como o indivíduo se autorrelaciona e se comunica com seu semelhante, por meio de conteúdo emocional que garante autoconsciência e pertinência social. Ele diz que existem duas inteligências, a racional e a emocional, e que uma completa a outra e quando uma delas, principalmente a emocional, é mais dinamizada, a outra aumenta seu potencial simultaneamente, sendo que por esse caminho o tabu do racional sobre o emocional cai por terra.

Ele afirma que outra questão importante em relação ao QE (quoeficiente emocional) e o QI (quoeficiente de inteligência) é que eles não são opostos, mas sim interdependentes e de certa forma distintos. Portanto é nessa relação que ocorre o natural, o dialético e o eclético relacionamento do ser humano.

Uma visão da natureza humana que ignore o poder das emoções é lamentavelmente míope. A própria denominação Homo sapiens, a, espécie pensante, é enganosa à luz do que hoje a ciência diz acerca do lugar que as emoções ocupam em nossas vidas. Como sabemos por experiência própria, quando se trata de moldar nossas decisões e ações, a emoção pesa tanto - e às vezes muito mais - quanto a razão. Fomos longe demais quando enfatizamos o valor e a importância do puramente racional - do que mede o QI - na vida humana. Para o bem ou para o mal, quando são as emoções que dominam, o intelecto não pode nos conduzir a lugar nenhum. (GOLEMAN, 1995, p. 18) 
Goleman (1995, p. 20) ressalta que as emoções são, em sua gênese, impulsos, deixados pela evolução, para ação instantânea e planejamentos imediatos a serem utilizados no cotidiano do ser humano. "A própria raiz da palavra emoção é do latim movere - 'mover' - acrescida do prefixo 'e', que denota 'afastar-se', o que indica que em qualquer emoção está implícita uma propensão para um agir imediato.”

Na vida cotidiana é possível constatar que a elevação da temperatura emocional tende a baixar o desempenho intelectual e impedir a reflexão objetiva. O poder subjetivador das emoções (que volta a atividade do sujeito para suas disposições íntimas, orgânicas) incompatibiliza-se com a necessária objetividade das operações intelectuais; e como se a emoção embaçasse a percepção do real, impregnando-lhe de subjetividade e, portanto dificultando reações intelectuais coerentes e bem adaptadas. [...] Analogamente, é possível constatar que a atividade intelectual voltada para a compreensão das causas de uma emoção reduz seus efeitos, uma crise emocional tende a se dissipar mediante atividade reflexiva. [...] Assim, a relação entre emoção e razão é de filiação, e, ao mesmo tempo, de oposição. Na expressão de Dantas 'a razão nasce da emoção e vive da sua morte’. (GALVÃO, 1999, p. 67).

O Portal Aprende Brasil, (Mais, 2008) falando sobre inteligência(as), ressalta que a nossa cultura, principalmente no aspecto educacional, tem dado maior importância à razão, pois o aprender a aprender e o aprender a pensar sempre estiveram e ainda estão presentes. Nesse sentido, os sistemas tradicionais de ciência e filosofia foram elaborados sobre o conceito de verdade. "Conhecimento era caracterizado como crença verdadeira e justificado; verdade e justificação obtidas pelo uso adequado da razão. Muitas áreas de estudo não eram consideradas científicas exatamente porque não podiam ser justificadas adequadamente pelo uso da razão. A razão passou a ser a principal fonte de conhecimento". Em relação ao ensino, toda sua construção passou a se organizar por meio da racionalidade.

Nota-se pelo exposto, que o ser humano tem na emoção e na razão seus principais condutos às suas apreensões e manifestações cognitivas, espirituais, objetivas, subjetivas, estéticas, morais, políticas e outras. Em outras palavras, o interior e o exterior contemplam-se no gênero humano por meio da emoção e da razão. Por outro lado, independente de origem filosófico-teórica e proveniência epistemológica e científica, fica patente a intersecção e influência recíproca entre esses âmbitos da natureza humana. 
As emoções, portanto, são importantes para a racionalidade. Na dança, entre sentimento e pensamento, a faculdade emocional guia nossas decisões a cada momento, trabalhando de mãos dadas com a mente racional e capacitando - ou incapacitando - o próprio pensamento. Do mesmo modo, o cérebro pensante desempenha uma função de administrador de nossas emoções - a não ser naqueles momentos em que elas lhe escapam ao controle e o cérebro emocional corre solto. . (GOLEMAN, 1995, p. 18).

Em entrevista cedida pela revista Pátio - Ed. Artes Médicas, Gardner (2008) ressalta as Múltiplas Inteligências dizendo que cada indivíduo é singular e em se tratando de inteligências cada um tem a sua, e estas são diferenciadas. Ele relata que, no caso da educação a teoria das inteligências múltiplas implica o seguinte: "todos nós temos tipos diferentes de mente, e o bom professor tenta se dirigir à mente de cada criança de forma mais direta e pessoal possível [...] mais crianças sentem que suas forças pessoais estão sendo reconhecidas”.

$\mathrm{Na}$ sequência, ele diz que a maior dificuldade é conhecer cada educando como ele realmente é, saber o que ele é capaz de fazer e centrar a capacidade nos interesses de cada um deles. Por outro lado, diz que o professor é um antropólogo que estuda cada aluno cuidadosamente, e um orientador que ajuda o educando a atingir seus próprios objetivos e os objetivos idealizados pela sociedade por meio da escola. Portando formas criativas e inovadoras devem passar pela educação, subsidiando educadores e educandos, renovando dinamizando e disseminando o processo ensino-aprendizagem.

\section{2 - A linguagem musical no processo ensino aprendizagem}

Atualmente algumas teorias relacionadas ao processo ensino-aprendizagem apresentam-se diferenciadas em relação às tradicionais ${ }^{4}$, pois partem de outros parâmetros no estudo das apreensões cognitivas e do conhecimento de modo geral. Nesse caso podem-se acompanhar as palavras de Gardner (1994, p. 76-81) - o idealizador das Inteligências Múltiplas - quando comenta que, no ato da linguagem sempre está presente o trato vocal e mensagem auditiva, mesmo ela sendo transmitida de forma escrita ou gestual. Ele acredita que os elementos auditivos e orais possuem papéis fundamentais na linguagem e que

4 Entende-se por teorias tradicionais de ensino-aprendizagem, aquelas que se concentram em formas lógico-matemáticas e linguísticas, quando da produção e disseminação do conhecimento. 
esses elementos agem diretamente nas inteligências linguística e musical. Ao mesmo tempo diz que a música e a linguagem humana podem ter evoluído de uma forma expressiva comum.

Campbell e Dickson (2000, p. 132), sobre as inteligências múltiplas, acrescentam que a música é, indubitavelmente, uma das formas artísticas que mais tempo tem na existência humana, utilizando-se da voz e do corpo como elementos naturais para a autoexpressão. Arte que já nasce com o homem. No útero materno, convivemos um bom período ouvindo as batidas do coração, assim como a respiração dos nossos pulmões e os movimentos mais delicados do nosso metabolismo, juntamente com os ciclos cerebrais. Portanto, o ser humano é sensível à música e todos podem desenvolver esses dotes em si mesmos e nos seus semelhantes.

\begin{abstract}
A música é muito mais que um simples conjunto de sons que se unem em uma melodia. Ela penetra nossa pele, provoca arrepios de prazer ou nos faz mergulhar em doces lembranças. Algumas melodias não nos tocam, enquanto outras nos atingem diretamente - e podem até mesmo transmitir significados concretos. "O cérebro de todo ser humano se interessa muito por informações musicais e é extremamente habilidoso em compreender seu significado", explica Stefan Kölsch, do Instituto Max Planck de Ciências Cognitivas e Neurológicas, em Leipzig. Kölsch investiga a ligação entre a música e a fala. O músico e psicólogo descobriu que o cérebro não faz grande diferença entre as duas: ambas são trabalhadas na mesma região. (SCHALLER, 2005, p. 64-69).
\end{abstract}

Segundo Bigand (2005, p. 59-61) a música se instala em nós sem percebermos tal efeito. Então, pessoas sem formação musical podem identificar acordes, melodias e temas da mesma forma que músicos profissionais. Nesse sentido, alguns estudos advindos da neurociência corroboram no sentido de identificar similitudes entre os caminhos neurobiológicos no processamento da linguagem e as percepções musicais. Dizem ainda, que atividades musicais estimulam a memorização, resolução de tarefas espaciais, capacidade de atenção, operação de categorização e raciocínio. Por fim, o autor diz que, sendo músico ou não, todos podem aprender com a música, pois os circuitos neurais envolvidos nas atividades sonoras são delineados previamente à aprendizagem explicita da música.

Diante disso, é fácil observar que a linguagem, principalmente textual da qual a sociedade contemporânea se utiliza, pode ser potencializada por meio da utilização da linguagem musical que serve a processos de ensino-aprendizagem 
e a elaboração de metodologias alternativas e importantes à educação.

De acordo com Valkíria (2007, p. 39-41), no pensamento de Swanwick a música pode ser concebida como: "discurso, troca de idéias, expressão do pensamento e forma simbólica”. Principalmente por sua forma simbólica ela permanece no tempo e no espaço em diversas culturas. Não obstante, a música se apresenta como caminho seguro ao pensamento, ao conhecimento e ao sentimento.

Creio que a música persiste em todas as culturas e encontra um papel em vários sistemas educacionais não por causa de seus serviços ou de outras atividades, mas porque é uma forma simbólica. A música é uma forma de discurso tão antiga quanto a raça humana, um meio no qual as idéias a cerca de nós mesmos e dos outros são articuladas em forma sonoras. (SWANWICK, 2003, p. 29 apud VALKÍRIA, 2007, p. 40).

Embora o presente texto não tenha como objetivo o ensino da música propriamente dito, é importante referendar a figura de Swanwick, como diz Valkíria (2007, p. 40), o qual indica três formas de se trabalhar a educação musical: o discurso, o discurso musical do aluno e a experiência musical (fluência musical - ouvir, articular, ler e escrever). Contudo, no ensino básico o conteúdo interdisciplinar, principalmente de canções, por si só oferece determinado discurso que pode ser reinterpretado e recriado pelo aluno sem entrar no mérito do estudo musical propriamente dito.

Além de provocar emoção, a música exerce papel fundamental na cognição, como apontam Campbell e Dickson (2000, p. 133), relatando que na Hungria observa-se, no trabalho de Zoltan Kodály, que nas escolas as crianças cantam todos os dias. Já na terceira série os alunos produzem sons belos e agradáveis. Nota-se que, os mesmos, vão muito bem em ciências e matemática, devendose a isso sua prática diária do canto. A percepção musical possui suas próprias normas e estruturas mentais de pensamento, nem sempre ligadas a outras formas de inteligência. Nesse sentido os autores destacam Stravinsk, o qual certa ocasião disse que "A música expressa a si mesma".

A linguagem musical é auricular, baseada em três elementos indispensáveis: som, movimento e timbre ou qualidade sonora. Possui simbologia própria. Qualquer pessoa normal que ouviu, com frequência, sons melódicos e harmoniosos está apta a desenvolver os elementos já citados e consequentemente exercer com certa habilidade as funções musicais, incluindo a elaboração, a entoação e interpretação através dos instrumentos. Os fundamentos dessa prática podem 
ser estabelecidos nos primeiros anos de vida.

Os respectivos autores (CAMPBELL; DICKSON, 2000) dizem que a atividade musical realizada em casa, ou em qualquer ambiente que a pessoa esteja, proporciona fundamentos importantíssimos na formação do indivíduo e seguramente apresenta-se como excelente instrumento didático-pedagógico capaz de provocar grandes avanços em ambiente escolar. Devido à intensa ligação entre a música e as emoções, a musicalização no ambiente escolar pode criar situações positivas para a aprendizagem. Assim poderá proporcionar ou intensificar as emoções como suspense, a cólera, o drama e/ou o contentamento, assim como pode ser usada para provocar o humor, acuidade auditiva e concentração.

Campbell e Dickson (2000) colocam que alguns filósofos da antiguidade acreditavam que a música era fundamental para a educação. Platão observava que, "o ritmo e a harmonia penetram profundamente nos recessos da alma e lá se estabelecem, fazem surgir a graça do corpo e da mente que só pode ser encontrada em alguém educado da forma correta”. Aristóteles também evidenciou a educação musical, crendo que graças à música as pessoas desenvolvem ótimas aprendizagens pessoais.

Já Confúcio apresentava a música como transformadora da personalidade e da política, dizendo que o ser humano de boa estatura deve propagar a música em busca da perfeição e da cultura. Se isso acontecer, as pessoas poderão testemunhar que a música provocou o elevo e a busca de novos ideais, que farão com que surja uma grande nação. Complementando, os autores mencionados relatam que na Idade Média e Renascença, a música era a base da aprendizagem, incluindo a geometria, a astronomia e a matemática.

Nos tempos atuais ela vem sofrendo muitos cortes nos programas educacionais, geralmente é a primeira a ser eliminada e quando não, enfrenta cortes no orçamento. As pessoas que propõem a volta às bases, também eliminaram a educação musical em vários estabelecimentos para transferir suas atividades para a leitura, aritmética e às ciências. Ironicamente, acredita-se que a música seja um excelente veículo para desenvolver essas qualidades.

Campbell e Dickson (2000, p. 132) dizem que a linguagem musical pode ser parte integrante de qualquer ambiente educacional. Oferece receptividade na entrada dos estudantes em seu ambiente de ensino, traz efeitos calmantes após exercícios físicos, alivia os ânimos da turma, renova a energia e diminui as tensões advindas das atividades escolares, principalmente nas provas e outras atividades avaliativas. Grande parte das pessoas já teve oportunidade de verificar que a música auxilia em várias atividades físicas, como digitar, realizar exercícios aeróbicos e práticas de natação.

Os movimentos e os andamentos sonoros das melodias proporcionam benesses no direcionamento e concatenação das atividades. Para a criança, sal- 
tar, marchar, andar com velocidade ou bailar ao som de melodias, desenvolve o sentido rítmico e graça. Para jovens e adultos, o som agradável favorece os afazeres tediosos e rotineiros. No que diz respeito à prontidão, também é muito eficiente, tanto na realização de atividades físicas ou para representar uma história. O desenvolvimento vai além do sinestésico, atingindo outras facetas do ambiente escolar.

Os mesmos autores (CAMPBELL; DICKSON, 2000, p. 140) destacam o pensamento de Don Shiltz quando este diz que a linguagem musical ajuda no estudo de vários conteúdos. Ela é componente histórico de qualquer época, portanto oferece condição de estudos na identificação de questões, comportamentos, fatos e contextos de determinada fase da história. Os estudantes podem apreciar várias questões sociais e políticas, escutando canções, música clássica ou comédias musicais.

Mesmo sem a intenção de trabalhar o canto especificamente, é interessante, se possível, tentar aplicar alguns elementos musicais, os quais Campbell e Dickson (2000, p. 140) alertam que implicam certa dificuldade por parte dos professores e alunos, que são habitualmente receosos na prática do canto ou execução musical. Quando o mestre resolve colocar o canto no ambiente escolar, deve lembrar que não tem a pretensão de formação profissional em relação à música, mas sim de estimular e dinamizar a performance nas atividades de ensino-aprendizagem.

Portanto percebe-se que a música é inerente ao ser humano e está presente em seu mundo desde sua gênese, e sem receio de engano, diz-se, acompanhando as ideias de muitos estudiosos, que ela é um dos elementos fundamentais na constituição do próprio Universo. Nesse sentido os gregos, principalmente através das ideias pitagóricas em relação à constituição cosmológica, diziam, na visão de Tomás (2002, p. 24), que a harmonia que organiza "o movimento dos astros não pode achar-se longe, dizia-se, da ordem que rege as relações dos mais simples intervalos fundamentais da música. Os astros que giram á volta dum centro comum devem, pois, mover-se a intervalos determinados segundo simples relações numéricas.”

A música com sua essência educativa teve papel fundamental na formação da sociedade grega e, por conseguinte, repercussão na formação cultural de toda a sociedade ocidental moderna, como se pode observar:

[...] a existência de uma cultura musical bem estruturada, sobretudo pelo fato de que a música ocupava um lugar capital na formação da sociedade. [...] O que se pode dizer em linhas gerais é que o pensamento musical grego concebe o fenômeno musical de um modo complexo e multiforme, 
visto que entre os gregos a música mantinha vínculos muito íntimos com a medicina, a astronomia, a religião, a filosofia, a poesia, a métrica, a dança e a pedagogia. [...] A formação do homem grego e, por conseguinte, todos os elementos que poderiam compor o termo "cultura” (ou na expressão mais adequada, paidéi $^{5}$ ) baseavam-se em um ponto de vista que considerava as coisas do mundo numa perspectiva tal que nenhuma delas lhes parecia como parte isolada do resto, mas sempre como um todo ordenado em conexão viva, na e pela qual tudo ganhava posição e sentido. (TOMÁS, 2002, p. 28-29).

Por outro lado, em relação à música e a interdisciplinaridade, ressalta-se que ela faz parte de nossa existência e está presente em todos os instantes de nossa vida: bailar, venerar os mortos, nas festas, rituais e outros. Presente no dia a dia de alguns grupos humanos, ainda nos dias atuais é utilizada e executada por todos. Praticamente todos os grupos humanos entram em consonância com a linguagem musical desde os primeiros anos de sua vida, até seu derradeiro suspiro.

A música pode e deve ser utilizada em vários momentos do processo de ensinoaprendizagem, sendo um instrumento imprescindível na busca do conhecimento, sendo organizado sempre de maneira lúdica, criativa, emotiva e cognitiva. Os currículos de ensino devem incentivar a interdisciplinaridade e suas várias possibilidades, pois a música ajuda em todas as fases e etapas do ensino, assim como é usada para alimentar o ímpeto patriótico, ilustrando as tradições e datas comemorativas, bem como apresentando-se através das diversas manifestações astístico-culturais.

A utilização da música, bem como o uso de outros meios artísticos, pode incentivar a participação, a cooperação, socialização, e assim destruir as barreiras que atrasam a democratização curricular do ensino. Para que isso aconteça, se faz necessário a revisão dos métodos, da fundamentação, das bases que orientam as várias atitudes didático-pedagógicas dos conteúdos disciplinares. A interdisciplinaridade ainda não se apresenta com muita visibilidade em nossa educação, tanto nas áreas de pesquisa como no ensino, o que acontece são justaposições multidisciplinares.

Nesse contexto, é importante que os diversos conhecimentos não se configurem em apenas amontoados de informações, transformados em receitas educacionais. Portanto se faz necessário a busca de novas formas metodológicas e didático-pedagógicas a serem introduzidas no meio educacional. Portanto, devem-se apresentar maneiras de transmitir e produzir o conhecimento, e também repensar a educação, se é que existe a tendência de superação da transmissão tediosa de conteúdo escolar.

A linguagem musical no processo de ensino apresenta-se como instrumental metodológico e pedagógico de significativa relevância, pois além de todas as

5 Hadot (1984) diz que o termo paideia identifica-se com educação e cultura geral. 
vantagens já colocadas, traz inerente a sua natureza e caráter, a interdisciplinaridade com a qual se dinamiza todo o processo de ensino-aprendizagem. Sem levar em conta que ela não busca com insistência a aplicação de maneiras, prescritivas e pré-estruturadas, na disseminação dos conteúdos a serem trabalhados.

\title{
3 - A criatividade musical como elemento interdisciplinar
}

Diante do exposto, a música insere-se como elemento criativo, subjetivo, emocional e interdisciplinar, fazendo parte da educação, pois a música é veículo pedagógico sempre presente desde os primórdios da humanidade, sendo que na educação formal ela se faz presente desde os tempos pretéritos da cultura clássica grega, a qual tinha na música o seu principal apanágio educativo e de formação cultural, contribuindo na organização social, construção de valores e formação do cidadão.

\begin{abstract}
A música auxilia na aprendizagem de várias matérias. Ela é componente histórico de qualquer época, portanto oferece condição de estudos na identificação de questões, comportamentos, fatos e contextos de determinada fase da história. Os estudantes podem apreciar várias questões sociais e políticas, escutando canções, música clássica ou comédias musicais. O professor pode utilizar a música em vários segmentos do conhecimento, sempre de forma prazerosa, bem como: na expressão e comunicação, linguagem lógico-matemática, conhecimento científico, saúde e outras. Os currículos de ensino devem incentivar a interdisciplinaridade e suas várias possibilidades. [...] A utilização da música, bem como o uso de outros meios, pode incentivar a participação, a cooperação, socialização, e assim destruir as barreiras que atrasam a democratização curricular do ensino. [...] A prática interdisciplinar ainda é insípida em nossa educação (CORREIA, 2003, p. 84-85).
\end{abstract}

A importância, função e natureza da música estão presentes em todas as indicações legais e nos fundamentos teórico-metodológicos constantes nos documentos norteadores da educação brasileira e em suas respectivas unidades federativas, a exemplo do Estado do Paraná, o qual relata que: 
A música no contexto escolar, defendida nessas Diretrizes, objetiva a educação dos sentidos e não está dissociada do lugar onde é composta e interpretada nem está desarticulada dos valores de um determinado grupo social. Exemplos disso são os textos de canções do repertório de cultos religiosos e de manifestações de cunho político e social. (PARANÁ-DCE, 2007, p. 43).

Portanto, incentivar a criatividade por meio da música é uma atividade muito salutar e promissora em ambiente onde se pratica o ensino-aprendizagem. Sabe-se que mesmo não se obtendo muita informação sobre o tema, pode-se dizer, sem temor de engano, que a música oferece bons instrumentos à criatividade e vice-versa, pois ela traz consigo o inusitado.

Segundo Kneller (1971, p. 94-99), uma ideia ou ato são criativos, quando são adaptados a uma situação singular. O pensamento é impaciente, inovador e criativo e é seduzido pela surpresa e novidade. O raciocínio não criador tende a ser sistemático lento e conservador. Por essa via o sistema educacional sufocou a criatividade espontânea dos alunos. Sendo que esse ato nem sempre foi culposo ou deliberado, simplesmente passou desapercebido, pois foi apenas no terceiro quartel do século XX que os educadores aprofundaram os estudos sobre a criatividade no ensino-aprendizagem.

Explorando as ideias de Kneller (1971, p. 100-107) quando este diz que os estudantes, principalmente os de mais idade, não são suscetíveis às ideias novas, preferindo os assuntos mais concretos e conhecidos, o professor deve acatar as ideias novas de seus alunos - e mais, deve induzi-las a esse fim - em todos os momentos e assuntos, dos quais, para tanto, poderá utilizar-se de maneiras apropriadas.

Como expressão do tempo contemporâneo, a estética da sensibilidade vem substituir a da repetição e padronização, hegemônica na era das revoluções industriais. Ela estimula a criatividade, o espírito inventivo, a curiosidade pelo inusitado, a afetividade, para facilitar a constituição de identidades capazes de suportar a inquietação, conviver com o incerto, o imprevisível e o diferente. [...] Por esta razão, procura não limitar o lúdico a espaços e tempos exclusivos, mas integrar diversão, alegria e senso de humor a dimensões de vida muitas vezes consideradas afetivamente austeras, como a escola, o trabalho, os deveres, a rotina cotidiana. Mas a estética da sensibilidade quer também educar pessoas que saibam transformar o uso do tempo livre num exercício produtivo porque criador. [...], a estética da sensibilidade é um substrato indispensável para uma pedagogia que se quer brasileira, portadora da riqueza de cores, sons e sabores. (BRASIL- 
MEC-PCNs, 1999, p. 75-76).

$\mathrm{Na}$ realidade, todos os pedagogos enfrentam um grande desafio de difícil solução. Por um lado existe a necessidade de exercitar a reflexão lógica e racional; em contra partida, estimular a capacidade criativa dos educandos. Têm-se, de um lado o rigor mental e intelectual versus a subjetividade, emoção e liberdade de expressão, portanto se faz necessário descobrir o equilíbrio entre os campos. Quanto mais estudarmos o tema criatividade e tudo o que a envolve, mais aceitável e procedente serão suas intervenções.

Para instigar a criatividade, é necessário provocar os alunos com pensamentos instigadores. Uma boa estratégia é transformar as informações em projetos que a turma poderá desenvolver. Nesse caso os estudantes poderão desenvolver suas ideias ao invés de recebê-las prontas. Além disso, é importante fazer com que o educando - num primeiro momento - internalize os conteúdos, sejam eles de várias naturezas, e posteriormente externalize-os, sendo que um instrumento eficaz para tanto pode ser sugerido por meio da música e seus elementos inter e multidisciplinares, bem como a aplicação de sua natureza emocional e racional, as quais proporcionam a criatividade, fazendo a elaboração e (re) elaboração dos saberes e consequentemente sua interferência no processo ensino-aprendizagem.

O ato criador necessita de autodireção, pois o indivíduo que cria, além de perceber e conceber, necessita avaliar suas ideias. A iniciativa é que provoca e realiza a aprendizagem criativa. É lógico que a presença da autoridade é muito importante, assim como o desenvolvimento das habilidades e a absorção das informações. Existe a produção cultural a dominar, assim como uma lógica no assunto tratado, que na maioria dos casos é melhor demonstrada pelo professor ou estudioso do assunto. Mas isto não impede que os alunos possam desenvolver seus próprios assuntos usando suas habilidades e conhecimentos. "A atividade criadora é uma necessidade humana, porque só criando, transformando o mundo, o homem faz um mundo humano e se faz a si mesmo" (PARANÁ-SEED, 1992, p. 152).

De acordo com Kneller (1971, p. 115), a incorporação de ideias formadas adicionadas a novas ideias é de fundamental importância para a renovação criativa do aprendizado e isso deve ser realizado em diversos campos experenciais, interagindo pensamento e sentimento, fertilizando seus anseios intelectuais e emocionais. Nesse sentido a escola tem o trabalho de estimular e indagar o educando, sempre explorando a intuição em busca de harmonia realizada através 
da conexão procurando desvelar o mistério.

Por outro lado, contrapondo-se a essa necessidade, o autor diz que o sistema de ensino prende e frustra o educando com muitas regras e normas desnecessárias. Ele sugere que os educandos e os educadores precisam de alforria, pois o sistema não está educando os indivíduos, mas sim, processando multidões. Finalizando, ele registra: "A educação deve consistir, no fundo, em pôr em ordem um fermento que já esteja agitando a mente”. (WHITEHEAD apud KNELLER, 1971, p. 106).

\section{Considerações finais}

Sem dúvida é inquestionável a relevância da música na educação, mas também é visível a sua ausência ou displicência quando de sua aplicação didático pedagógica em sala de aula. Nota-se que sua teorização e presença nos ideários e documentos educacionais oficiais não lhe garantem sua efetiva prática. Isso ocorre, acredita-se, devido à rigidez dos programas oficiais de ensino, moldados em estruturas arcaicas e conservadoras que não permitem outras maneiras de se praticar o desenvolvimento dos saberes em ambientes educacionais.

Por outro lado, nos últimos tempos, percebe-se maior flexibilidade em relação à produção do conhecimento, inclusive a aceitação de novas abordagens e tratamento teórico-metodológicos a diversos níveis, áreas e categorias dos saberes humanos e mundanos, os quais possibilitam o emprego da emoção, criatividade e mesmo da subjetividade no desenvolvimento do conhecimento. Nesse sentido, pode-se dizer que o processo ensino-aprendizagem pode gozar de ampliação e liberdade, aumentando suas possibilidades e que, nesse contexto a linguagem musical consubstanciada em elementos racionais e emocionais, pode colaborar renovando o trabalho pedagógico como um todo.

\section{REFERÊNCIAS}

BACHELARD, Gaston. A formação do espirito científico: contribuição para uma psicanálise do conhecimento. Tradução: Estela dos Santos Abreu. Rio de Janeiro: Contraponto, 1996. 316 p. 
BIGAND, Emmanuel. Ouvido afinado. Viver Mente \& Cérebro: revista de psicologia, psicanálise, neurociências e conhecimento, São Paulo, p. 58-63, jun. 2005.

BRASIL-MEC-PCNs Parâmetros Curriculares Nacionais: Ensino Médio. 2000. Disponível em: $<$ http://portal.mec.gov.br/seb/arquivos/pdf/baseslegais.pdf $>$. Acesso em: 10/01/ 2008 .

BRASIL, Ministério da Educação, Secretaria de Educação Média e Tecnológica. Parâmetros curriculares nacionais: ensino médio. Brasília: Ministério da Educação, 1999.

CAMPBELL, L.; CAMPBELL, B.; DICKINSON, D. Ensino e aprendizagem por meio das inteligências múltiplas: inteligências múltiplas na sala de aula. Tradução: Magda França Lopes. 2. ed. Porto Alegre: Artmed, 2000.

CAPRA, Fritjof. O ponto de mutação: a ciência, a sociedade e a cultura emergente. Tradução: Álvaro Cabral. São Paulo: Cultrix, 2002.

CORREIA, Marcos Antonio. Música na Educação: uma possibilidade pedagógica. Revista Luminária, União da Vitória, PR, n. 6, p. 83-87, 2003. Publicação da Faculdade Estadual de Filosofia, Ciências e Letras de União da Vitória. ISSN 1519-745-X

De MASI, Domenico. Entrevista: Por um mundo mais crítico. Revista Nova Escola. Disponível em: <http://www.ensino.net/novaescola/136_out00/html/fala_mestre.htm>. Acesso em: 06/04/2008.

GALEFFI, R. A filosofia de Immanuel Kant. Brasília: Universidade de Brasília, 1986.

GALVÃO, Izabel. Henri Wallon: uma concepção dialética do desenvolvimento infantil. 5. ed. Petrópolis: Vozes, 1999.

GARDNER, Howard. Estrutura da mente: a teoria das inteligências múltiplas. Tradução: Sandra Costa. Porto Alegre: Artes Médicas Sul, 1994.

. Entrevista sobre inteligências múltiplas. Entrevista cedida pela revista Pátio - Ed. Artes Médicas. Disponível em: <http://www.abrae.com.br >. Acesso em: 10/01/2008.

GOLEMAN, Daniel. Entrevista sobre inteligência emocional. Cedida pela Editora Objetiva. Disponível em: <http://www.abrae.com.br>. Acesso em: 10/01/2008.

. Inteligência emocional: a teoria revolucionária que redefine o que é ser inteligente. Tradução: Marcos Santarrita. 69. ed. Rio de Janeiro: Objetiva, 1995.

JAPIASSÚ, Hilton; MARCONDES, Danilo. Dicionário Básico de Filosofia. 3 ed. Rio 
de Janeiro: Jorge Zahar, 1999.

KNELLER, G. F. Arte e ciência da criatividade. 2. ed. São Paulo: Ibrasa (Instituto Brasileiro de Difusão Cultural), 1971.

LOBATO, Walkiria Teresa Firmino. A formação e a prática pedagógico-musical de professores egressos da pedagogia. 157 p. Dissertação (Mestrado em Educação - Área de concentração: Aprendizagem e Trabalho Pedagógico) - Universidade de Brasília. Brasília, 2007. Disponível em: <http://bdtd.bce.unb.br/tedesimplificado/tde_busca/ arquivo.php? > . Acesso em: 04/11/2008.

NOVA ESCOLA. Edição Especial - Grandes Pensadores 2: Vida e obra de educadores que fizeram história, da Grécia Antiga aos dias de hoje. v. 2. São Paulo: Abril, 2006.

PARANÁ-SEED. Secretaria de Estado da Educação, Superintendência de Educação, Departamento de Ensino de Primeiro Grau. Currículo básico para a escola pública do Estado do Paraná. Curitiba: Imprensa Oficial do Estado do Paraná, 1992.

SCHALLER, Katrin. Acordes curativos. Viver Mente \& Cérebro: revista de psicologia, psicanálise, neurociências e conhecimento, São Paulo, p. 64-69, jun. 2005.

TOMÁS, Lia. Ouvir o lógos música e filosofia. São Paulo: Unesp, 2002.

Texto recebido em 23 de julho de 2008. Texto aprovado em 13 de novembro de 2008. 